\title{
EFFECT OF BIO- FILLER ON TENSILE AND COMPRESSIVE BEHAVIOR OF BIDIRECTIONAL E-GLASS REINFORCED
}

\section{WITH EPOXY PLASTICS}

\author{
LOKESH. K. $\mathrm{S}^{1} \&$ SHRINIVASA MAYYA. $\mathrm{D}^{2}$ \\ ${ }^{I}$ Assistant Professor, Department of Mechanical Engineering, Srinivas Institute of Technology, Mangaluru, India \\ ${ }^{2}$ Professor, Department of Mechanical Engineering, Srinivas Institute of Technology, Mangaluru, India
}

Fibre reinforced plastics are considered as light weight industry ready products by offering its remarkable high strength for the less weight, corrosion resistance, easy of processing and better control over the geometry of the parts to be made. Blending of polymers or compounding polymers with different fillers is a rather simple way to produce new polymeric materials with desired properties. Production and uses of particulate-filled polymer composites have increased intensively because of favorable cost/performance ratio. The cost reduction, as a primary interest of adding mineral fillers to polymers, has transformed during the time into increasing demands to fulfill a function role of polymer matrix composites. The unique and diverse characteristics of composites materials have increased in many folds. In the present research, experiment has been successfully carried out by synthesizing E-glass/epoxy composites with mussels shells powder added in different percentage (i.e. $0 \%, 6 \%, 12 \%, \& 18 \%$.). Mechanical tests have been conducted according ASTM standard. It was observed from the results that adding of mussel shell powder influence greatly on the basic properties of polymer matrix material. The samples under tensile loading with varied filler percentage has no much effect on improving tensile strength where as sample loaded with upmost quantity bears higher compressive strength than the rest
\end{abstract}

KEYWORDS: Bio-Fillers, Mechanical Behavior, FRP's \& Filer Composites

Received: Jun 14, 2018; Accepted: Jul 24, 2018; Published: Aug 02, 2018; Paper Id.: IJMPERDAUG201895

\section{INTRODUCTION}

Composites comprising of mixing of one or more materials combined with a macroscopic range with the help of special techniques enlarges the qualitative internal properties of the resultant material under the set of testing conditions such a way that one of the background material acts as the matrix to bind and gives actual shape of the material and other as reinforcement which bears the applied external load. Preparation of composites involves proper selection of polymer and reinforcing material and addition of filler material to the matrix system, however, the increase in filler content in the GE composite enhances the young's modulus, flexural strength, surface hardness, brittleness and decreases the tensile strength and elongation at break. Results proves that increase in filler content in the GE composite enhances the young's modulus, flexural strength, surface hardness, brittleness and decreases the tensile strength and elongation at break [1]. Under flexural loading conditions, while assessing the behavior of composite material, it is clear that the addition of filler material will greatly improve the bending strength of glass fibers and thereby results higher stiffness values. Three point bending method probably provides a 
better estimate of the actual material behavior under flexural loading [2]. Graphite, as an additive to polymer composites, has led to eclectic effects on mechanical properties of graphite/epoxy composites, at the same time as affirmative effects on tribological properties of graphite/epoxy composites. Palm fiber reinforced epoxy composites with or without graphite has shown an amended mechanical performance. Tensile strength and elongation at the break play a significant role in the friction behavior of fillers/epoxy composite materials [3]. Stiffness can be readily improved by adding micron sized particles since rigid inorganic particles generally have a much higher stiffness than that of polymer matrices [4-5]. However, the strength strongly depends on the stress transfer between the particles and the matrix. For well-bonded particles, the applied stress can be effectively transferred to the particles from the polymer matrix resin [6]. However, for poorly bonded micro-particles, Strength reduction occurs [7-8]. The drawback of thermosetting resins is their poor resistance to crack growth [9-10]. But inorganic particles have been found to be effective toughness for thermosetting resins [11]. It was summarized from the literature that, the addition of fillers in to polymer matrix system structured by fibrous layers would ensure best mechanical properties. Addition to this adding filler in different percentage by weight would enhance upmost characteristics of the reinforced plastics. The objective of present work is to assess the ultimate tensile strength and compressive strength of E-glass with addition of mussel shell as filler, by varying $0 \%, 6 \%, 12 \%$, and $18 \%$ by weight followed by hand lay-up technique.

\section{FABRICATION OF SPECIMENS}

Samples are prepared by employing hand layup technique which is conventional and relatively cheaper and easy process of developing composites. The selection of materials both as a reinforcement and matrix is glass fabric with 360 gsm and epoxy resin (araldite gy250) with the help of hardener (teta) was effectively utilized. To serve the purpose of utilizing bio-filler material to commercially viable product, work has been carried out to make use of mussel shell as a filler material which is available abundantly with free of cost[12]. Concerning its core nature of reflecting better mechanical properties when it is infiltrated with thermo set resin, preparing polymer composites reinforced with e-glass fiber has been successfully done by loading the powdered form of e-waste rubber limiting its size to $150 \mu \mathrm{m}$ in the proportion of $6 \%, 12 \%, 18 \%$ by weight of resin matrix by employing most well-known and conventional method, hand lay-up technique. To implement this, mussel shells from coastal region are initially collected and powdered to limited grain size and then it is loaded with different weight percentage of matrix material calculated with volume fraction of 60:40 with respect to fiber material considered [13]. The prepared mussel shell powder is collected in a bowl which is as shown in figure 1. The die arrangement for preparing fiber reinforced plastic materials is shown in figure 2. By volume fraction calculation, 16 layers of 250x250 mm sized e-glass woven fabric laminates were cut by using electric hacksaw machine which is as shown in figure 3 and the corresponding amount of epoxy resin was weighed. The different percentage $(6 \%, 12 \%$, and $18 \%)$ of filler material was added to the resin and hardener mixture. 10:1 ratio of resin and hardener ratio is considered by premixing and stirred thoroughly to faster the curing action of prepared samples. In order to ensure the surface of the laminates are free from impurities, each laminate should be cleaned and that could be done as primary operation before binding them at room temperature and pressure it should be cleaned completely and the surfaces of the laminate will be completely cleaned to ensure that the laminates are free from any impurities. This process is primary operation that could be carried out before binding of laminates which is conducted at room temperature and the thickness of the laminates is maintained with $4 \mathrm{~mm}$. Hand layup technique is employed where the glass fiber infiltrated with epoxy resin was compressed and allowed to cure for certain period of time. The process of sample preparation by hand layup is as shown in figure 4. 


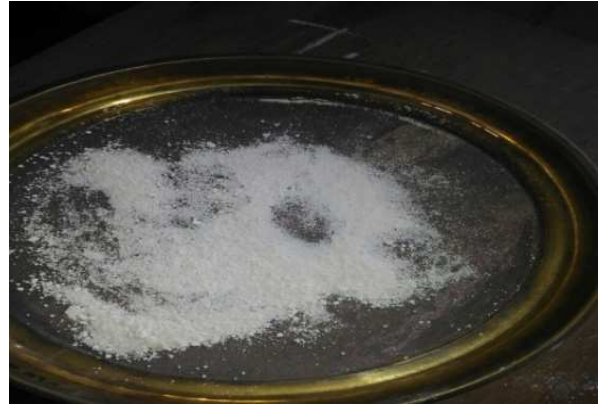

Figure 1: Mussel Shell Powder



Figure 3: Electric Hacksaw Machine

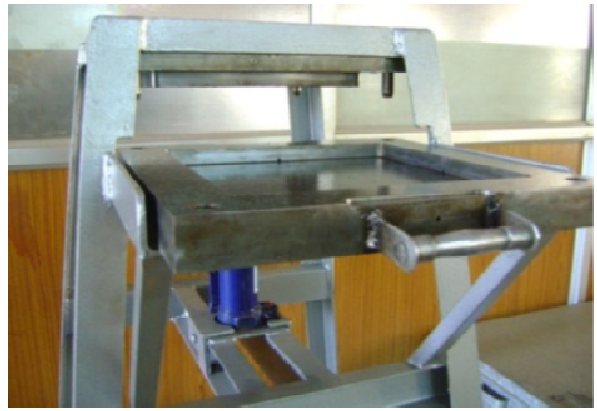

Figure 2: Die Arrangement



Figure 4: Hand Lay-Up Method

\section{EXPERIMENTAL METHOD}

Figure 5 depicts the testing of prepared samples by using digital UTM. Tensile and Compression test has been conducted to evaluate the mechanical behavior of samples which are cut according to ASTM standards prior to the testing. Conducting tensile test gives the major impact on assessing the inter laminar behavior of samples where the sample is subjected to external loading applied with controlled passion by recording the values obtained under loading condition results in significant deflection of the sample.

According to ASTM D3039 samples were cut with uniform thickness of 4mm in order to conduct tensile testing. Samples are prepared with varying filler percentage by weight $(0 \%, 6 \%, 12 \%$, and $18 \%)$ and the similar composition has been carried to perform compression test which directs the quality of the material upon compressive loading.

The extreme ends of the samples are kept neatly to perform tight grip while conducting the test this enables the proper assessment of the material to counteract the applied load. Load corresponding to obtained elongation of the sample was clearly noticed to redeem the stress-strain behavior of the sample experimented for all the different filler percentage.

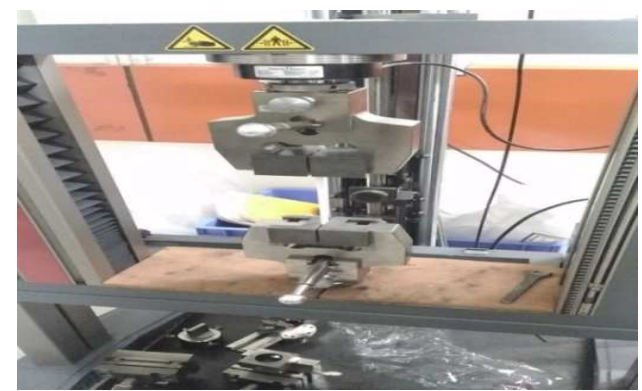

(a)

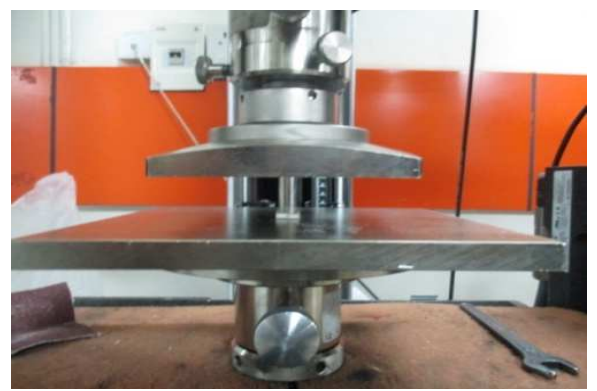

(b)

Figure 5: Testing of Samples (a) Tensile \& (b) compression by Digital UTM 


\section{RESULTS \& DISCUSSIONS}

\section{Tensile Test}

Tensile test is conducted to assess the mechanical behavior of the fiber reinforced plastics of having different weight percentage of bio-filler loaded using digital UTM. Discussion below highlights the graphical characteristics of each sample varied in composition.

\section{Sample without Filler Material}

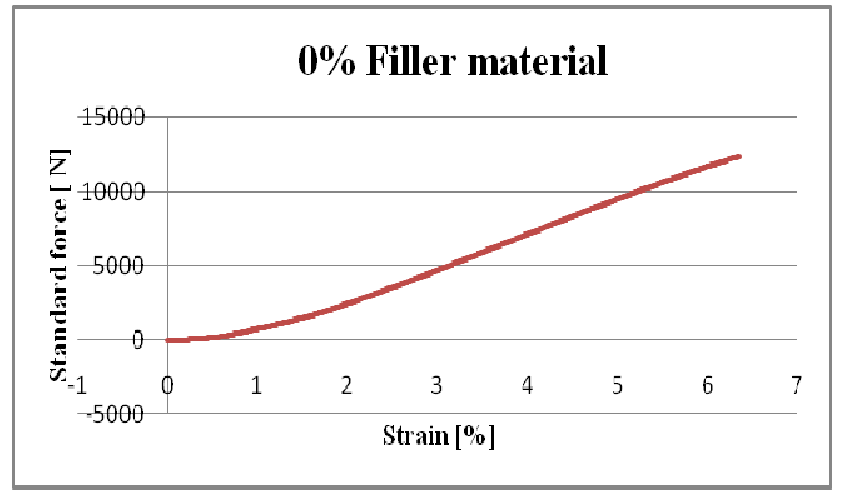

Figure 6: Standard Force v/s Strain

Figure 6 depicts the tensile behavior of E-glass/epoxy composite without adding filler material. It is clearly observed from the graph that the rapid increase in the load taken by the sample corresponding to measurable increase in strain, hence it is clear from the graph that the maximum load taken by the sample is found to $\mathrm{b} 12.2 \mathrm{KN}$ and with corresponding strain at break $6.4 \%$. It was also noticed for the sample without filler content; the maximum stress induced for the above said load is recorded about $300 \mathrm{MPa}$ with the significant increase in the value of the strain.

\section{Sample with 6\% Filler Material}

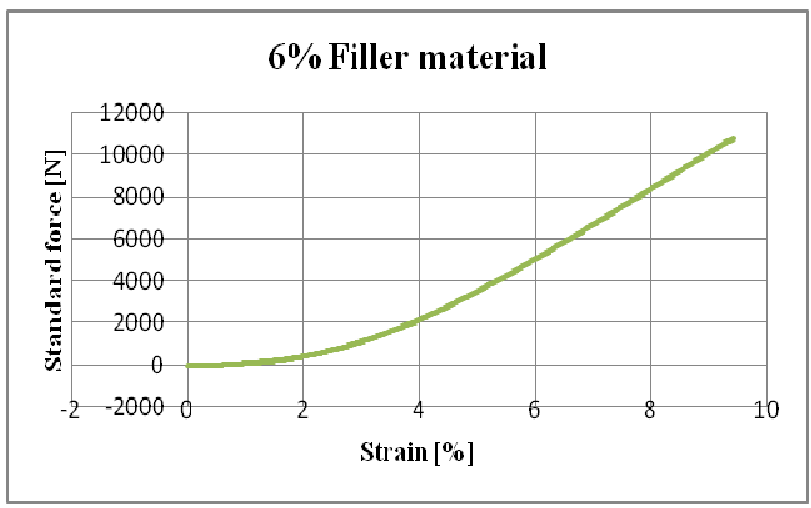

Figure7: Standard Force v/s Strain

Figure 7 highlights the behavior of E-glass epoxy composite filled with $6 \%$ filler under tensile loading. It is recorded properly that there is a decrease in the load taking ability of material as compared to that of unloaded material by recording the maximum load of about $10.75 \mathrm{KN}$ for the corresponding strain at break is found to be $9.4 \%$. 


\section{Sample with $12 \%$ Filler Material}



Figure 8: Standard Force v/s Strain

The tensile behavior of E-glass epoxy composite added with $12 \%$ filler material as shown in figure 8 . It was clear that the peak load of this specimen is found to be $9.88 \mathrm{KN}$ with the corresponding strain at break of $8.4 \%$ which clearly indicated the progressive decrement in the load taking ability of the sample due to uneven dispersion of the filler leading to rapid slippage of reinforcement over the matrix upon increasing the filler percentage.

\section{Comparison of Tensile Test Results with Varied Filler Percentage}

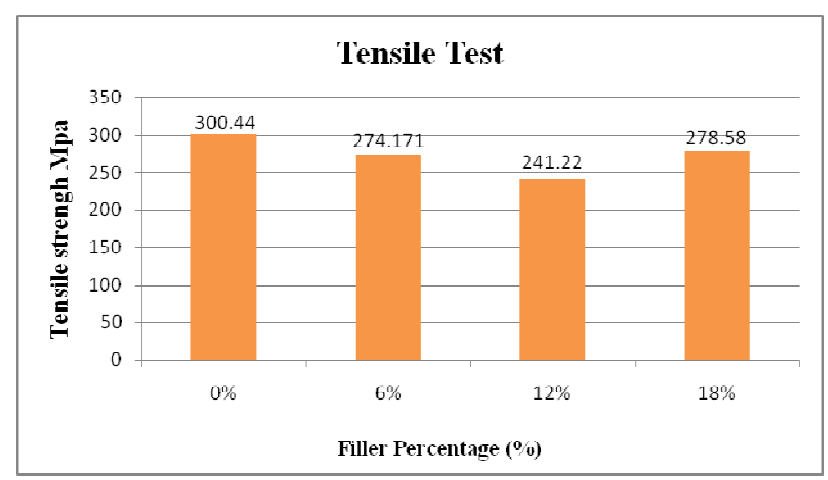

Figure 9: Tensile Strength v/s Filler Percentage

The qualitative comparison of tensile test results by varying the filler percentage is as shown in figure 9. It was observed that the sample without containing filler records maximum tensile strength of $300.44 \mathrm{Mpa}$ whereas sample loaded with 6\% filler exhibits the UTS of 274.171Mpa. The value of UTS is found to be $241.22 \mathrm{Mpa}$ and $278.58 \mathrm{Mpa}$ for the sample loaded with $12 \%$ and $18 \%$ respectively. It is clearly concluded that sample containing no filler exhibit sufficient strength but the matrix fails to sustain the load upon increasing the filler percentage due to rapid slipping at the inter laminates resulting in minimal load bearing capability of a material. 


\section{Compression Test}

For E-glass/Epoxy Composite having 0\% Filler Material

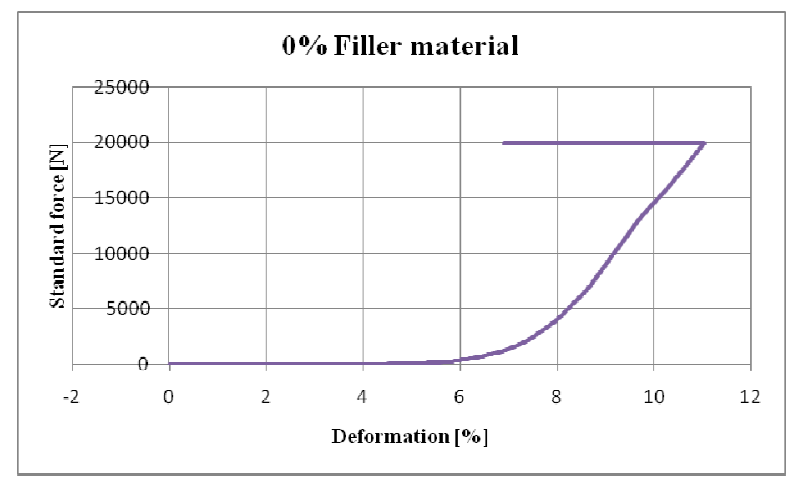

Figure 10: Standard Force v/s Deformation

Figure 10 shows the compression behavior of E-glass epoxy composites without mussel shell powder which records the peak load of $19.963 \mathrm{KN}$ and with corresponding deformation of $11 \%$. The fracture of specimen is found to be $20 \mathrm{KN}$.

\section{For E-glass/Epoxy Composite having $6 \%$ Filler Material}



Figure 11: Standard Force v/s Deformation

The behavior FRP's with adding of $6 \%$ of filler under compressive loading is as shown in figure 11. It is noticed from the graph that there will be sudden increase in the curve with significant increase in the deformation. The maximum load taken by the sample is found to be $19.962 \mathrm{KN}$ with corresponding deformation of $5.6 \%$ and also the fracture of specimen is found to be $20 \mathrm{KN}$. 


\section{For E-glass/Epoxy Composite having 12\% Filler Material}

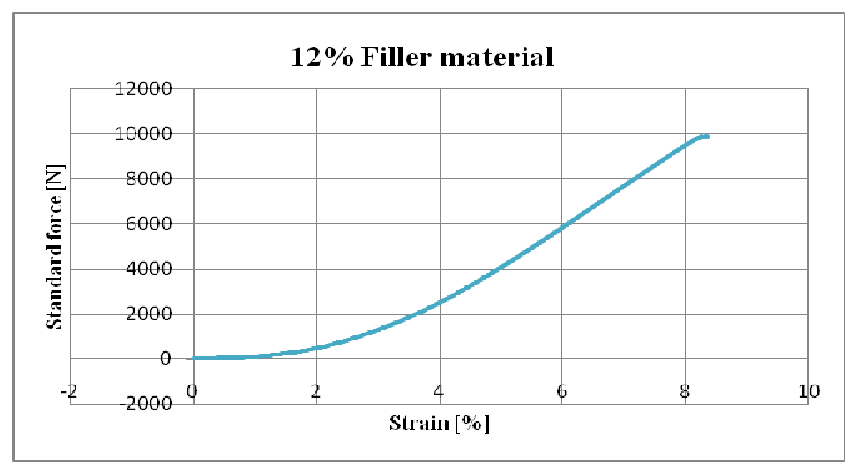

Figure 12: Standard Force v/s Deformation

Figure 12 shows the compressive behavior of E-glass epoxy composites with adding of $12 \%$ of filler. It was clearly observed from the graph that the maximum load taken by the sample is $19.964 \mathrm{KN}$ and with corresponding strain of $4.9 \%$. The fracture of specimen is found to be $20 \mathrm{KN}$.

\section{For E-glass/Epoxy Composite having $18 \%$ Filler Material}

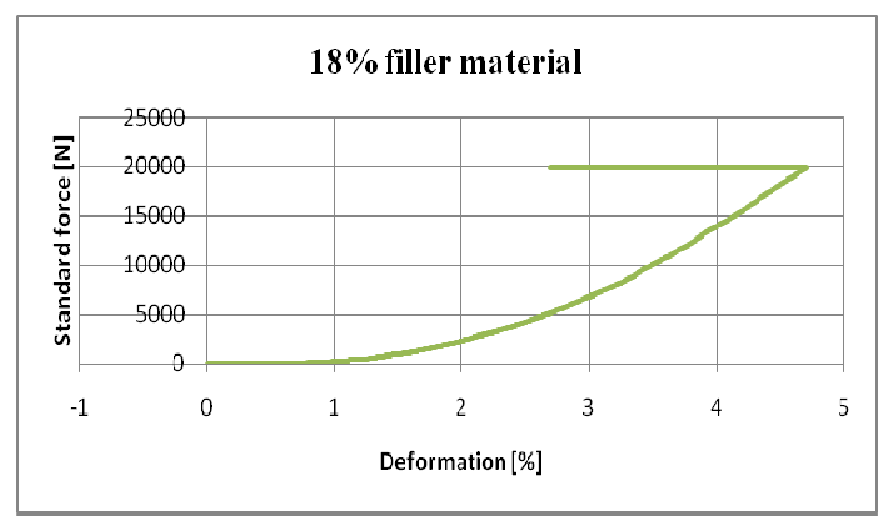

Figure 13: Standard Force v/s Deformation

Figure 13 highlights the compressive behavior of sample loaded with $18 \%$ filler. It is observed from the graph that there will be minute changes in the value of load taken by the sample when compared to that of sample loaded with $12 \%$. The deviation in the load taking ability renders the over accumulation of filler across the matrix which records about $19.8 \mathrm{KN}$ of load with the corresponding deformation of $4.3 \%$. The fracture of specimen is found to be $20 \mathrm{KN}$.

\section{Comparison of Compressive Test Results}

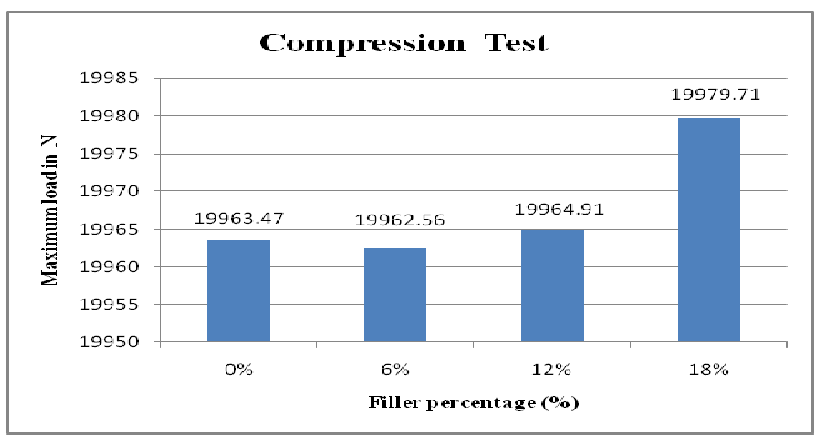

Figure 14: Load Filler v/s Percentage 
To obey the experimental extraneous parameters, comparison of test results shown in figure.14 upon compressive loading is considered to be vital for different samples by varying the filler percentage. It was observed that the sample containing $18 \%$ of filler is better than that of $0 \%, 6 \%, \& 12 \%$. Due to accumulation of filler powder throught the matrix such that effective barrier against compressive loading was maintained with fibre assembly. The maximum compressive strength was recorded for the sample containing $18 \%$ is found be $19979.71 \mathrm{Mpa}$.

\section{CONCLUSIONS}

The Effective utilizing of mussel shells as Bio filler material which is available in abundance within added according to volume fraction of 60:40 ratio by employing conventional hand layup technique. Commercial utilizing of Bio filler has been successfully achieved by adding the desirable finer grain size of 106 microns of mussel shells in different percentage by weight to the polymer matrix. Research work has been successfully carried out by synthesizing E-glass/epoxy composites with mussels shells powder added in different percentage (i.e. for $0 \%, 6 \%, 12 \%, \& 18 \%$.). The following conclusion has been made upon conducting mechanical test which are concluded as follows;

- While comparing the tensile test results by varying the filler percentage. It was observed that the sample containing with no filler exhibit better strength than that of rest of the samples. The sample $0 \%$ filler material is shows the tensile strength of $300.44 \mathrm{Mpa}$ and $6 \%, 12 \%$ filler material is $10 \% \& 20 \%$ less compare to the sample without filler.

- While comparing the compression test by varying the filler percentage. It was observed that the sample $18 \%$ containing filler material is better strength than that of the other rest. The sample $18 \%$ containing filler shows the better compression strength of $19979.71 \mathrm{Mpa}$ and $0 \%, 12 \%$ filler material is $50 \%$ less strength then $18 \%$ containing filler material respectively.

\section{REFERENCES}

1. B. Shivamurthy, (2009), Influence of SiO Fillers on Sliding Wear Resistance and Mechanical Properties of Compression Moulded Glass Epoxy Composites, Journal of Minerals \& Materials Characterization \& Engineering, 8, No.7, 513-530.

2. KS Lokesh, B Ummaji, P Gururaj, K Rayappa, Effect of Red Mud Particles on Scratch Resistance of Aluminum Based Metal Matrix Composites, American Journal of Aerospace Engineering, 2018

3. Mahdi Alajmi, (8 July 2015), Correlation between Mechanical Properties with Specific Wear Rate and the Coefficient of Friction of Graphite/Epoxy CompositesMaterials(Basel) 2015 Jul; 8(7): 4162-4175.

4. Eirich, F. R. (1984) Some Mechanical and Molecular Aspects of the Performance of Composites. Journal of Applied Polymer Science, 39, 93-102

5. Spanoudakis, J. and Young, R. J. (1984) Crack Propagation in a Glass Particle Filled Epoxy-Resin. Effect of Particle-Volume Frtion and Size. Journal of Materials Science, 19, 473-486. http://dx.doi.org/10.1007/BF02403234

6. Hsueh, C. H. (1989) Effects of Aspect Ratios of Ellipsoidal Inclusions on Elastic Stress Transfer of Ceramic Composites. Journal of American Ceramic Society, 72, 344-347.

7. Danusso, F. and Tieghi, G. (1986) Strength versus Composition of Rigid Matrix Particulate Composites. Polymer, 27, 13851390.

8. Nicolais, L. and Narkis, M. (1971) Stress-Strain Behaviour of Styrene-Acrylonitrile/Glass Bead Composites in the glassy 
Region. Polymer Engineering and Science, 11, 194-199.

9. Davangeri, M. B., Vinay, B. U., \& Bhat, V. (2014). Development And Evaluation Of Mechanical Properties Of Asbestos Filled E-Glass/Epoxy Composites. Development, 4(1), 25-30.

10. Maloney, A. C., Kausch, H. H. and Kaiser, T. (1987) Parameters Determining the Strength and Toughness of Particulate filled Epoxide Resins. Journal of Materials Science, 22, 381-393.

11. Shimbo, M., Ochi, M. and Shigeta, Y. (1981) Shrinkage and Internal Stress during Curing of Epoxide Resins. Journal Of Applied Polymer Science, 26, 2265-2277.

12. Spanoudakis, J. and Young, R. J. (1984) Crack Propagation in a Glass Particle Filled Composite at or Near a Rigid Sphericalinclusion. Journal of Materials Science, 19, 487-496.

13. KS nbspLokesh, KS LokeshCritical Review On Automobile Applications Of Hybrid Fibre Reinforced Plastics- International Journal of Creative Research Thoughts (IJCRT) 6 (1), 302-307

14. KS Lokesh, T Pinto, M Gowspeer,Effect of E-waste Rubber on Wear Behaviour of Glass fibre Reinforced with Epoxy Composites - IJASRE, 2018

15. KS Lokesh, BY Karthik, CG Avinash Experimental Study on Tribological Characteristics of E-waste filled Fibre Reinforced Plastics, International Journal of Scientific Research in Mechanical and Materials - 2018

16. Lokesh K. S, Dr. Thomas Pinto, \& Ravi S. M. (2017). Evaluation of Mechanical Properties and Wear Characterization of Polymer Composites under Varying Temperature Conditions: A Review. International Journal of Engineering and Information Systems (IJEAIS), 1(4), 64-68. http://doi.org/10.5281/zenodo.821168 
